\title{
A cidadania na formação de jovens do ensino médio na dimensão do cotidiano escolar de escolas de Novo Hamburgo/Brasil ${ }^{1}$
}

\author{
The citizenship in the formation of high school students in the school \\ routine dimension at schools in Novo Hamburgo/Brazil
}

\author{
Janaina Andretta Dieder ${ }^{1}$ (i) ; Dinora Tereza Zucchetti ${ }^{1}$ (i) ; Elisandro Schultz \\ Wittizorecki $^{2}$ (1); Gustavo Roese Sanfelice ${ }^{1}$ \\ ${ }^{1}$ Universidade Feevale, Brasil; ${ }^{2}$ Universidade Federal do Rio Grande do Sul (UFRGS), Brasil
}

\begin{abstract}
Resumo
O estudo tem como objetivo analisar os desdobramentos da cidadania no cotidiano escolar, entendendo a cidadania como prática cotidiana. Caracteriza-se como qualitativo descritivo e interpretativo. Foram selecionadas duas escolas de ensino médio, uma da rede de ensino pública e uma da rede privada de uma cidade do Vale do Sinos/RS. A imersão no campo empírico se constitui através de análise de documento (PPP), observações registradas em diários de campo e entrevistas com um membro da equipe diretiva e dois docentes de cada escola. Quanto às características das escolas, pode-se afirmar que a escola pública possui uma cultura escolar já instituída na sociedade/comunidade local, que implica em regras de convívio social bem definidas e rígidas, necessárias - em sua perspectiva - para o que se espera quanto à inserção no mundo do trabalho. Já na escola privada, a reorganização do seu espaço e funcionamento ao flexibilizar regras busca tornar o aluno mais autônomo. Na escola pública, a existência das regras é muito mais no sentido de dever do que de convívio, o que acaba limitando a cidadania plena. Na privada, há diálogo, construção, questionamentos e autonomia dos alunos para se expressarem dentro da escola numa nítida busca pelo protagonismo do aluno.
\end{abstract}

Palavras-chave: cidadão; escola; educação; ensino médio.

\section{Abstract}

This study aimed at analyzing the unfolding of citizenship in the school routine, understanding the citizenship as a daily practice. It is characterized as qualitative descriptive and interpretative. Two high schools were selected: a public school and a private school in a city located in Vale do Sinos/RS. The immersion in the empirical field is performed through the document analysis (PPP), observations registered in field journals and interviews conducted with a member of the management team and two teachers from each school. Concerning the characteristics of the schools, it can be affirmed that the public school has a school culture already instituted in the society/local community, that implies well-defined and strict social interaction rules, necessary - in its perspective - to what is expected regarding the insertion in the job market. While in the private school, the reorganization of its space and functioning when softening the rules seek to make the students more autonomous and responsible for their acts. It results from the investigation that, in the public school, the existence of rules is much more in the sense of duty than of social interaction, which limits the full citizenship. In the private school, there is dialogue, construction, questioning and autonomy of students to express themselves inside the school in a clear pursuit for their protagonism.

Keywords: citizen; school; education; high school.

Como citar (APA):

Dieder, J.A., Zucchetti, D.T., Wittizorecki, E.S. \& Sanfelice, G.R. (2021). A cidadania na formação de jovens do ensino médio na dimensão do cotidiano escolar de escolas de Novo Hamburgo/Brasil. Revista Iberoamericana de Educación, 85(2),119-139. https://doi.org/10.35362/rie8523686

\footnotetext{
${ }^{1}$ O presente trabalho contou com apoio financeiro da CAPES - Código de financiamento 001 para sua realização.
} 


\section{Introdução}

O processo de consolidação do capitalismo reivindicou a "escola pública, gratuita, leiga, universal e obrigatória da época moderna", situando as relações entre educação e a formação do cidadão às lógicas do mercado e do trabalho, "ainda que nem sempre isto tenha significado preparar tecnicamente para o trabalho, mas disciplinar, tornar obediente a normas e hierarquias, adquirir hábitos e condutas próprias do mundo produtivo" (Silva, 1995, p. 132). Esses processos podem ser percebidos na escola ainda hoje, já que "no interior da escola são conscientemente mobilizados preceitos e roteiros de comportamento que terão como propósito o desenvolvimento de um ethos civilizatório que é exterior ao próprio lugar público ocupado pela escola" (Boto, 2018, p. 158).

Em vista disso, torna-se importante a discussão acerca dos entrelaçamentos da cidadania e do cotidiano escolar, que é composto por relações, regras, normas, tensões, saberes tácitos e outros explícitos. A cidadania como prática cotidiana, isto é, uma "cidadania em construção" sugere a "valorização da dimensão processual na qual o resultado final não se reporta já a uma noção fixa de cidadania, ou a um modo preestabelecido de agir como ou ser cidadão/cidadã", mas sim uma problematização e construção da sua própria cidadania (Menezes \& Ferreira, 2014, p. 135). Portanto, a cidadania pode e merece ser trabalhada na escola para além do espaço da sala de aula, das disciplinas e conteúdos didáticos, abrangendo todo o cotidiano escolar, ou seja, desde o momento em que o aluno entra nesse ambiente e seu convívio, o recreio, os corredores, as relações sociais e afetivas, a organização do lugar com suas regras e normas, e tudo que fizer parte desse contexto. Valorizando, assim, as formas pelas quais a "cidadania é construída na prática pelos jovens em seus mais variados aspectos do dia a dia e pensar como otimizar as condições de exercício dessa cidadania para se ter uma sociedade cada vez mais democrática" (Maia \& Pereira, 2014, p. 629).

Em vista disso, este estudo buscou analisar os desdobramentos da cidadania no cotidiano escolar em uma escola pública e em uma escola privada de uma cidade do Vale do Sinos/RS². Dentre os aspectos que compõem o cotidiano escolar observado, foi utilizada a observação etnográfica sugerida por Mattos (2016), registrando: o espaço físico utilizado; relação das pessoas

\footnotetext{
${ }^{2}$ Cujos critérios de seleção estão explícitos na metodologia.
} 
com o espaço e entre si; toques dos sujeitos uns nos outros; linguagem corporal e linguagem verbal; relacionamento dos sujeitos entre si; tom de voz; vocabulário.

Os contextos estudados possuem características diferentes, implicando diretamente no cotidiano escolar e nos desdobramentos da cidadania. A escola pública utiliza a abordagem tradicional de ensino, no qual o método se baseia "na exposição verbal da matéria e/ou demonstração", dando "ênfase nos exercícios, na repetição de conceitos ou fórmulas e na memorização" que "visa disciplinar a mente e formar hábitos", sendo que "predomina a autoridade do professor que exige atitude receptiva dos alunos" (Leão, 1999, p. 192). Portanto, a escola segue um modelo conhecido e ainda predominante nas escolas, organizado em forma de classes, onde os alunos sentam enfileirados, os horários são pré-estabelecidos e rígidos, tanto para entrada, saída, recreio e troca de períodos, as disciplinas são separadas, existem regras para diferentes circunstâncias e movimentos do cotidiano escolar, as quais devem ser seguidas à risca. Já a escola privada inseriu no ano de 2018 uma experiência centrada em metodologias ativas e colaborativas em seu processo de ensino, sendo assim, não existem mais turmas, os horários são flexíveis (não há mais sinal escolar), a interdisciplinaridade é trabalhada em determinados momentos, e as regras são flexíveis buscando o diálogo para a resolução dos conflitos.

\section{Metodologia}

Este estudo caracteriza-se como qualitativo descritivo e interpretativo. Silverman (2009) sinaliza que a pesquisa qualitativa tem recursos para descrever como o fenômeno é localmente constituído. No caso deste estudo, como se constituem os desdobramentos da cidadania na dimensão do cotidiano escolar, tendo como contexto uma escola da rede de ensino pública e uma de rede privada em uma cidade do Vale do Sinos.

Para tanto, foram selecionadas duas escolas de ensino médio, uma da rede de ensino pública e uma da rede privada da cidade, tendo como critério de escolha as escolas com maior número de alunos matriculados no Ensino Médio no ano de 2018, presumindo-se, assim, que essas são as escolas mais procuradas e com maior alcance quantitativo na formação dos alunos da respectiva cidade, atuais/futuros cidadãos. 
Para a coleta de dados foram utilizados documentos, feitas observações descritas em diários de campo e realizadas entrevistas. Os documentos analisados foram os Projetos Político-Pedagógicos (PPP) das escolas participantes do estudo.

As observações nas escolas ocorreram duas vezes por semana em cada escola, compreendendo os seguintes períodos em 2018: 13/03 à 13/06 na escola pública e 21/03 à 14/06 na escola privada. As entrevistas foram realizadas com um membro da equipe diretiva e dois docentes de cada escola, indicados por meio da ferramenta bola de neve que "utiliza cadeias de referência" para que os "novos contatos" tenham "as características desejadas" (Vinuto, 2014, p. 203), conforme tabelas abaixo:

Tabela 1. Codificação das entrevistas

\begin{tabular}{lllcc}
\hline \multicolumn{1}{c}{ Função } & Pseudônimo & Escola & Data & Tempo de entrevista \\
\hline Supervisora & Julia & Pública & $12 / 07 / 2018$ & $*$ \\
Professora & Eliza & Pública & $10 / 07 / 2018$ & $55 \mathrm{~min} 28 \mathrm{seg}$ \\
Professora & Celia & Pública & $12 / 07 / 2018$ & 42min09seg \\
Diretora & Lorena & Privada & $9 / 07 / 2018$ & $55 \mathrm{~min} 28 \mathrm{seg}$ \\
Professor & Leonel & Privada & $9 / 07 / 2018$ & 1hora03min59seg \\
Professor & Edvaldo & Privada & $9 / 08 / 2018$ & 37min08seg \\
\hline
\end{tabular}

* Supervisora não quis que a entrevista fosse gravada, portanto as respostas foram somente anotadas.

Fonte: elaborada pelos autores.

A presente pesquisa segue os parâmetros éticos conforme Resolução 510/2016 do Conselho Nacional de Saúde, ciente sobre as obrigações éticas, preservando o respeito às pessoas. Foi aprovada pelo Comitê de Ética em Pesquisa da Universidade Feevale, sob o número 81015617.1.0000.5348. Para a análise e interpretação dos dados, utilizou-se a triangulação que, neste estudo, ocorreu através da triangulação por fontes, teórica e reflexiva (Cauduro, 2004). 


\section{Resultados e discussão}

A partir das observações realizadas nas duas escolas, analisamos e interpretamos que os desdobramentos da cidadania (Menezes \& Ferreira, 2014; Maia \& Pereira, 2014) na dimensão do cotidiano escolar constituem-se de maneiras diferentes, apresentadas primeiramente no quadro 1.

Quadro 1. Síntese dos elementos de análise

\begin{tabular}{|c|c|c|}
\hline $\begin{array}{l}\text { Elementos de obser- } \\
\text { vação do cotidiano } \\
\text { escolar }\end{array}$ & Escola pública & Escola Privada \\
\hline Metodologia de ensino & Tradicional & Ativa e colaborativa \\
\hline Recreio & Horários rígidos & Horários flexíveis \\
\hline Entrega de trabalhos & $\begin{array}{l}\text { Entregues na folha padrão } \\
\text { da escola, somente para } \\
\text { o professor no horário de } \\
\text { sua disciplina. }\end{array}$ & $\begin{array}{l}\text { Entregues em folhas de } \\
\text { caderno para o professor } \\
\text { ou secretário da escola em } \\
\text { qualquer horário (conforme } \\
\text { combinações). }\end{array}$ \\
\hline Ar condicionado & $\begin{array}{l}\text { Ligado somente pelo } \\
\text { monitor após o início da } \\
\text { aula. }\end{array}$ & $\begin{array}{l}\text { Alunos e professores } \\
\text { podem ligar e controlar } \\
\text { temperatura. }\end{array}$ \\
\hline $\begin{array}{l}\text { Sair da sala com } \\
\text { mochila }\end{array}$ & Proibido & Permitido \\
\hline Limpeza da sala & Obrigatório & Não é cobrado \\
\hline Uso do celular & $\begin{array}{l}\text { Proibido (somente uso } \\
\text { pedagógico permitido pelo } \\
\text { docente). }\end{array}$ & $\begin{array}{l}\text { Guia do aluno: vedado } \\
\text { o uso indevido; mas na } \\
\text { prática os professores } \\
\text { dizem que é permitido e os } \\
\text { alunos usam. }\end{array}$ \\
\hline $\begin{array}{l}\text { Uso de equipamentos } \\
\text { da escola }\end{array}$ & $\begin{array}{l}\text { Alunos só podem utilizar } \\
\text { acompanhados pelo } \\
\text { professor. }\end{array}$ & $\begin{array}{l}\text { Alunos podem utilizar e } \\
\text { ficam à disposição. }\end{array}$ \\
\hline $\begin{array}{l}\text { Idas aos banheiros e } \\
\text { tomar água }\end{array}$ & $\begin{array}{l}\text { Alunos só podem sair com } \\
\text { carteirinha do professor, } \\
\text { um aluno por vez. }\end{array}$ & $\begin{array}{l}\text { Alunos podem sair a } \\
\text { qualquer momento sem } \\
\text { permissão. }\end{array}$ \\
\hline Atrasos na chegada & $\begin{array}{l}\text { Aluno só pode entrar com } \\
\text { a presença dos pais. }\end{array}$ & $\begin{array}{l}\text { Entrada permitida com } \\
\text { aluno sozinho. }\end{array}$ \\
\hline $\begin{array}{l}\text { Consumo de bebidas e } \\
\text { comidas em sala }\end{array}$ & Proibido & Permitido \\
\hline Uniforme & Uso obrigatório & Facultativo \\
\hline
\end{tabular}

Fonte: elaborado pelos autores. 
A partir do quadro de síntese dos elementos que compõem o cotidiano escolar, foram escolhidos alguns itens mais relevantes e contraditórios que influenciam na cidadania para serem analisados descritivamente e discutidos, sendo eles: uso do celular, consumo de bebidas e comidas em sala de aula e presença do uniforme.

A partir da caracterização das escolas realizadas anteriormente, compreendemos que as metodologias de ensino implicam em diferenças nos desdobramentos da cidadania no cotidiano escolar dos contextos pesquisados, já que a escola pública apresenta maior rigidez, enquanto que a privada tem mais flexibilidade nos procedimentos. Sendo assim, constata-se na escola pública uma cultura escolar já incorporada pelo coletivo. Seja pelo fato de a escola seguir o padrão tradicional de ensino, já conhecido por todos (professores, alunos, pais e comunidade escolar), que se constitui em um "conjunto de dizeres e fazeres [...] pelas ações dos principais protagonistas das disciplinas escolares, professores e alunos" (Pinto, 2014, p. 140); seja pelo próprio funcionamento e organização da escola, que também segue esse modelo, sendo "capaz de reunir processos idênticos que produzem consensos envolvendo o sistema de significação do mundo e da realidade, regulando condutas e organizando a vida social" (Malikoski \& Kreutz, 2014, p. 248).

Malikoski e Kreutz (2014) contribuem com a ideia de que a cultura escolar promove a organização do espaço escolar através de determinadas regras e seus efeitos, percebida nas observações da escola pública durante o cotidiano escolar, já que, de uma forma geral, os alunos já sabiam das regras, das restrições, do funcionamento e da organização do contexto, sem questionar muito sobre. Essa cultura escolar parte de um dado consenso sobre as funções da instituição escola. Aescola pública investigada partilhava dessa cultura já arraigada na sociedade, constituindo uma cultura escolar particular na cidade, onde pudemos acompanhar que todos se inculturavam ao ingressar nela, uma vez que alguns alunos já eram conhecidos de outra escola e suas posturas na outra instituição que estudavam, o caracterizavam como "bagunceiros". Na escola em que a pesquisa era realizada, os mesmos partilhavam dessa cultura já instituída. Em contrapartida, observamos na escola privada certa dificuldade no andamento das atividades e compreensão da proposta por parte dos alunos, principalmente no começo, já que uma dada cultura escolar foi rompida com a mudança das metodologias e 
da organização escolar, portanto, levará um tempo até essa nova cultura escolar, embasada na autonomia do aluno através das metodologias ativas e colaborativas, ser consolidada.

Dando sequência aos achados do estudo, passamos a olhar para o cotidiano escolar na dimensão das regras de convívio social demarcadas pelas instituições e sua relação com a cidadania, já que a partir da cultura escolar e dessa imagem socialmente construída "a escola tende a abordar a cidadania, quando muito, como mais um tema a ser ensinado, e não como o exercício de atores concretos face às suas demandas no espaço público" (Leão \& Santos, 2018, p. 793). Ou seja, através dessa cultura arraigada no chão da escola, a cidadania não é vista como uma construção cotidiana que pode e deve ser trabalhada também na perspectiva dessas normas - ou melhor, da construção coletiva delas. Vale lembrar que a escola é um local que traz uma segunda socialização para os alunos, preparando-os para a vida social. Deste modo, dentro do âmbito escolar "há o aprendizado dos preceitos que deverão regular a sociabilidade", já que a "vida dos adultos se dispõe a partir de certos códigos; e esses códigos precisarão ser aprendidos"; sendo fundamental a atenção também para os "possíveis fatores de resistência, de recusa, de transgressão" (Boto, 2018, p. 157).

Ambas as escolas apresentam algumas diretrizes para o convívio no âmbito escolar apresentado no PPP da escola pública (2017) e no guia do aluno (2018) na privada ${ }^{3}$, apontando para uma distância entre os dois ambientes. A escola pública tem como característica marcante as regras, cobranças e rigidez das mesmas, sem muitos questionamentos, bem como constatou Candau (2002, p. 140) em seu estudo, no qual a escola "manifestava com força uma dinâmica de normatização e rotinização que lhe dava uma acentuada rigidez e pouca permeabilidade a aspectos relacionados à cultura social de referência, assim como a interesses mais conjunturais e contextualizados que emergiam no seu dia-a-dia".

\footnotetext{
${ }^{3}$ Importante ressaltar que a escola privada tem uma versão do PPP datada de $2007 \mathrm{em}$ seu site. Considerando que a escola modificou toda sua metodologia e, por orientação da direção, esse PPP deveria ser desconsiderado, já que o novo estava em construção e não pôde ser fornecido, pois não é de domínio público. Dessa forma, fomos orientados a utilizar o que consta no guia do aluno e também no site.
} 
Em relação ao uso do celular, na escola pública "não é permitida a utilização do celular e tão pouco recargar a bateria do telefone" (PPP escola pública, 2017). A escola segue a Lei estadual 12.884, de janeiro de 2008: "caso utilizem o celular na sala de aula, sem fins pedagógicos, este será recolhido pelo professor e só poderá ser entregue ao responsável legal pelo aluno, no turno do mesmo, 24 horas após o seu recolhimento" (PPP escola pública, 2017, p. 26). Durante as observações identificamos que, de forma geral, os alunos não utilizavam o celular. Em determinados momentos usavam escondido ou com permissão do docente para uso pedagógico. Por vezes, mesmo com a regra, os professores tinham que pedir ou ordenar que guardassem o telefone. Nesse sentido, vale ressaltar que a cultura escolar estabelecida nessa instituição é "marcada pela lógica da transmissão de informações" e "do controle sobre o fluxo comunicacional", ou seja, o ensino tradicional, "não dialoga bem com essa nova cultura, marcada pela horizontalidade, [...] que vem se instituindo em torno das tecnologias digitais, a chamada cultura digital" (Bonilla \& Pretto, 2015, p. 501). Nesse sentido, destacamos que a "escola já não tem a hegemonia na transmissão do conhecimento construído pela humanidade, pois novos agentes concorrem na socialização das novas gerações", tais como os aparatos tecnológicos (Stecanela, 2016, p. 353). Essas "práticas em rede podem tirar os professores da "zona de conforto", pois exigem romper com algumas hierarquias, tornando professores e alunos, colaborativamente, produtores de informações, conhecimentos e culturas" (Bonilla \& Pretto, 2015, p. 513).

Parece que na escola em questão existe esse receio, já que segue o modelo tradicional, no qual o professor é a autoridade e "transmite o conteúdo na forma de verdade a ser absorvida" (Leão, 1999, p. 192), portanto, veem na proibição a solução. Em contrapartida, observamos que alguns - poucos professores utilizam essa ferramenta como aliada no processo educativo, buscando romper essa concepção e se aproximar da realidade dos alunos, já que o acesso e o uso desse instrumento de forma adequada também é uma forma de exercer a cidadania.

No guia do aluno da escola privada está escrito que é vedado o uso indevido de aparelhos eletrônicos em sala de aula. Quando questionados, os docentes disseram que o uso era permitido. O guia não proíbe, apenas restringe ao uso impróprio, mas não explicita qual seria esse uso. Nas observações a utilização do celular ficou perceptível. Alguns professores não se incomodavam com isso, outros pediam para guardar ou diziam que iriam recolher e 
outros procuravam conscientizar os alunos sobre o uso, por meio do diálogo, conversa e demonstrações de como isso poderia atrapalhar a atenção deles (através de vídeos e textos). Nas entrevistas com os docentes, eles relataram que a briga com o celular era uma das maiores questões e desafios para se trabalhar, buscando um aluno que valorizasse a vida real e não a virtual, para se tornar um cidadão com mais empatia, mais sensível, mais humano. Conforme comenta o professor de biologia Edvaldo (9/08/2018):

\begin{abstract}
Eles têm um desafio que nunca antes houve na história da vida do planeta, que é aprender a interagir com o mundo onde a conectividade virtual, o celular, a internet é uma realidade, desde o ano zero deles. Eles não conheceram o mundo off-line, por exemplo, eu acho isso absurdamente transformador na construção da visão de mundo desse sujeito. Eles não conheceram, eles não tiveram determinadas sensações e experiências que o mundo off-line produz. E eu acho que isso resultou numa geração de pessoas ansiosas, que têm dificuldade de pensar no depois, que querem as coisas para imediatamente, se tem que pensar muito tempo sobre uma coisa eu já me desvio atenção, porque o cérebro deles se acostumou a enxergar o mundo dessa forma, o Youtube, a rede social, o Instagram, o feed que não termina, o troço é todo feito pra pegar o jovem, pra pegar o sujeito. E aí eles se acostumam com aquele comportamento. O cérebro deles constrói aquelas sinapses ali, eles entendem que é assim que as pessoas interagem, o mundo é isso aí mesmo, dia após dia reforça, ano após ano reforça. E aí eu caio de paraquedas aqui e espero sensibilizálos com questões ambientais e aí não funciona bem assim, eu acho que esse lado que dificulta. Mas eu acho que o saldo no fim das contas é positivo, assim, eu vejo que para a grande maioria deles aquilo que eu coloco como uma informação às vezes chocante, essa informação ressoa neles, como a que vai ter mais plástico que peixes no oceano.
\end{abstract}

O professor retrata a dificuldade de lecionar para essa geração que nasceu inscrita e partilhando na/da cultura digital, mas também reconhece que isso pertence ao cotidiano de seus alunos e que compreender e aliar isso ao processo de ensino é trabalhoso e lento. Já que as "mudanças de posturas e de concepções não são processos simples, nem tampouco podem acontecer em um curto espaço de tempo", onde a marca das redes é a velocidade, em que os jovens acompanham e requerem essa velocidade, portanto, os alunos "querem e pedem para a escola estar em rede, sejam elas as redes físicas ou as redes sociais" (Bonilla \& Pretto, 2015, p. 513) e, durante as observações, percebeu-se o esforço por parte dos professores para que isso ocorresse. Além disso, observou-se um empenho de grande parte dos docentes para conscientizar os alunos no sentido de não negligenciar suas atividades cotidianas e o "convívio social para estar permanentemente on-line" (Martins \& Mogarro, 2010, p. 196). Bem como a busca pela sensibilização 
dos alunos em todos os aspectos da vida, nesse caso relatado pelo professor Edvaldo, pelas questões ambientais, uma vez que estar consciente e comprometido com esse tema também é uma forma de desenvolver a cidadania (Giassi, Dajori, Machado, \& Martins, 2016).

Em relação ao consumo de bebidas e comidas em sala, na escola pública não é permitido em sala de aula que os alunos "masquem chicletes, comam balas e afins ou lanche durante as aulas e nem chimarrão. É permitido apenas o consumo de água", como também é proibido "fazer festas ou confraternizações com bebidas e comidas, ressalva quando combinado com a direção" (PPP escola pública, 2017, p. 26). Presenciei momentos em que isso era permitido somente na aula de sociologia de uma professora (a entrevistada Eliza), a qual realizava debates e discussões com lanches fora da sala de aula.

No final do mês de março foi instalada uma máquina de café (paga) na escola, que gerou algumas discussões, já que os alunos não podiam consumir o café em sala. Em observação numa turma de terceiro ano, algumas alunas contestaram que não tinha nada demais tomar café em sala, que era como tomar água, uma necessidade básica, que não iria incomodar ninguém. A docente Eliza (de sociologia, mencionada acima) argumentou que essas decisões vinham da direção e os professores somente as seguiam. Ela teve que chamar a atenção das alunas, para que elas não saíssem no intervalo entre as aulas para comprar café. Houve um diálogo aberto entre alunos e docente sobre a questão e a professora reafirmou que essa era uma decisão do coletivo e disse "sou amplamente democrática, mas como não dá certo com alguns, que ficam ali matando aula, não dá pra liberar. Em menos de três dias estragaram a máquina, alunos chegaram atrasados na aula por causa disso também" (Diário de campo, 28/03/2018). Percebe-se essa postura da docente condizente com o que se propõe para trabalhar a cidadania na escola, ou seja, por meio da discussão de algo que aconteceu no cotidiano educacional (Maia \& Pereira, 2014), pois ela abriu mão de certa forma de "seus conteúdos" e debateu com os alunos sobre a questão que estava gerando polêmica e divergência entre os discentes.

Em contrapartida, na escola privada, essas regras não se encontram estabelecidas no guia do aluno e são flexibilizadas na convivência, gerando maior proximidade entre alunos e professores. Pois além de haver momentos de confraternização planejados (como na pública), tanto os alunos como os 
professores trazem chimarrão para a sala e compartilham. Além disso, há café disponível para ambos, que podem sair da sala para buscar e tomar. É importante ressaltar que alunos e professores trazem suas xícaras, pois como foi relatado pela diretora da escola privada na entrevista:

\begin{abstract}
Estamos na campanha do copo zero, copo plástico, porque a gente faz todo um trabalho em sala de aula, sobre resíduos, conscientização nesse sentido, que é uma questão de cidadania porque é o futuro das novas gerações e o nosso consequentemente também. Então é incoerente nós termos copos plásticos disponíveis, por exemplo, hoje quem quer tomar café tem que trazer sua caneca, trazer seu copo e a gente vai trabalhando com os alunos, se ele não traz ele não toma café, por exemplo. E isso de uma forma muito tranquila, não é que não vai ganhar, só que tem que trazer, se não trouxer... Então dessa coerência entre o discurso e a prática, o que se diz e o que se faz em todos os espaços. (Lorena, 9/07/2018).
\end{abstract}

A questão trazida pela diretora da escola, que abarca a educação ambiental promovida, nesse caso, através da substituição de copos plásticos pelas canecas reutilizáveis de cada aluno/professor, é uma temática que deve ser considerada atualmente e no futuro na educação para a cidadania, como propõe Martins e Mogarro (2010). Assim, trabalhar a educação ambiental na escola para além do conteúdo teórico de uma disciplina específica, de forma prática, consciente e coerente por todos que compõem esse cenário, contribui na formação de cidadãos mais instruídos para encarar os desafios da sociedade atual "cujo maior dilema gira na solução dos problemas ambientais, pois envolvem aspectos econômicos, sociais, recursos naturais, éticos entre outros" (Giassi et al., 2016, p. 31).

Pensando na constituição desse sujeito e sua formação para a cidadania, outra questão que chama atenção pela diferença nas duas escolas diz respeito ao uniforme. Na escola pública:

O uniforme completo é obrigatório desde o início das aulas e também nas atividades no turno oposto. Caso o aluno não compareça uniformizado e se recuse a fazer uso de um emprestado pela escola, o mesmo será advertido e os responsáveis serão convocados a comparecer na escola para conversar com o vice-diretor, pois no ato da matrícula, os responsáveis ficam cientes quanto à obrigatoriedade do uniforme. (PPP escola pública, 2017, p. 23). 
De acordo com o que foi observado, os alunos seguem essa norma. Percebemos algumas resistências durante o inverno ${ }^{4}$, pois eles podem usar outros casacos por cima, mas é exigida a camiseta da escola por baixo. Importante destacar aqui que o uso do uniforme escolar, historicamente, tem papel regulador, já que é por meio dessa vestimenta que os alunos absorvem "noções e normatizações sobre o poder, os limites do dissenso, o permitido e o proibido, o pudor e a transgressão" (Beck, 2014, p. 142). Essas noções são cobradas e visíveis no cotidiano escolar através das regras e normas que constituem o contexto. Dessa forma, o uniforme se caracteriza como um dispositivo de controle, pelo qual "padronizam-se, identificam-se e diferenciam-se os/as estudantes" (Beck, 2014, p. 137).

Além dessa obrigatoriedade, há controle e rigidez no comprimento dos shorts das meninas. No dia 25 de abril, durante as observações no turno da tarde, em uma turma do $1^{\circ}$ ano, um aluno perguntou se estava permitido as meninas virem de short de novo. Pelo que compreendemos, havia sido proibido, pois o clima estava mais frio e, como nos últimos dias o calor tinha voltado, as meninas disseram que o uso tinha sido liberado no dia anterior. A professora que estava em sala naquele momento disse que "nunca pôde short", que era bermuda o permitido, que a vice-diretora (que segundo uma aluna age como diretora porque manda em tudo) iria passar e medir, pois o short deveria estar, no máximo, 4 dedos acima do joelho (Diário de campo, 25/04/2018). Nesse momento, a professora diz "somos todos adultos, quero mais é que ela passe e tire tudo da sala pra aprender" (Diário de campo, 25/04/2018). Ao final da aula, a vice-diretora passou na sala mesmo. Disse que as alunas não poderiam dobrar o short, senão iria cancelar a permissão do uso. Além disso, falou para uma aluna ir à costureira e pedir para colocar mais um pedaço de tecido em seu short. Entretanto, pelo que sabemos da comunidade escolar, os uniformes da escola são todos produzidos em um mesmo local.

Diante disso, cabe ressaltar duas questões. A primeira diz respeito à padronização dos alunos, pois com o uso do uniforme todos seguem um mesmo padrão, uma uniformidade, como aborda Beck (2014), não podendo destacar-se as identidades e alteridade desses jovens. O que poderia ser interessante, por um lado, pois não há uma "concorrência" entre as indumentárias, assim, preservando e garantindo a igualdade entre os alunos e

\footnotetext{
${ }^{4}$ No inverno, o Vale do Sinos/RS registra temperaturas próximas de zero grau.
} 
também criando uma identidade coletiva dos estudantes com sua instituição de ensino (Beck, 2014); mas, por outro lado, torna-se complicado, pois a padronização leva ao apagamento dessas identidades e diversidades, ou seja, "a liberdade de expressão de tais sujeitos pelas suas vestimentas não compunham os propósitos de tal ideário" - de igualdade (Beck, 2014, p. 143). Dessa forma, percebemos aqui a cidadania construída através de "um conjunto de comportamentos" que caracterizam o cidadão, isto é, aquele que segue tais premissas - no caso o uso do uniforme - é considerado cidadão e aqueles que não apresentam tal conduta são marginalizados "seja por falta de interesse, seja por falta de possibilidade" (Ferreira \& Castellani Filho, 2012, p. 138).

Além disso, pudemos acompanhar nessa escola que os alunos possuem muito mais deveres, no sentido da normatização do comportamento/enquadramento social, limitando a construção de cidadania, que prevê também direitos a esses alunos e, principalmente, espaços de discussões para esses discentes questionarem, terem autonomia e liberdade de se expressar dentro da escola, tendo voz e vez nos processos decisórios, recuperando o protagonismo desses sujeitos (Rifiotis, 2007). Conforme apontam Maia e Pereira (2014, p. 619), a cidadania "não é um status a ser conquistado por quem assimila e incorpora em sua prática certos padrões de comportamento, mas sim uma forma de ser e estar no mundo que desde sempre transparece na existência dos indivíduos".

A segunda questão se refere ao controle do tamanho do short utilizado pelas alunas. É certo que temos regras e é importante sabermos como é indicado nos vestir em determinados lugares e/ou situações, entretanto, esse controle excessivo evidencia o machismo ainda presente nessa instituição escolar. Relembramos aqui um caso ocorrido no ano de 2016, numa escola privada de Porto Alegre/RS, no qual alunas realizaram uma mobilização pelo uso de shorts, criando uma petição online "Vai ter shortinho, sim"5. As alunas relataram situações de constrangimento: "tem vários casos de meninas que já foram retiradas da sala de aula, e pediram que elas vestissem uma calça de moletom ou que fossem para casa, porque com aquela roupa não

\footnotetext{
${ }^{5}$ Notícia: Alunas fazem mobilização pelo uso de shorts em escola de Porto Alegre (25/02/2016). Disponível em: <http://g1.globo.com/rs/rio-grande-do-sul/noticia/2016/02/ alunas-fazem-mobilizacao-pelo-uso-do-shorts-em-escola-de-porto-alegre.html>. Acesso em: 1 out. 2018.
} 
dava para ficar"6, situações semelhantes às presenciadas na escola pública pesquisada. Nesse sentido, compartilhamos com o que elas pleiteiam na petição: "que a instituição deixe no passado o machismo, a objetificação e sexualização dos corpos das alunas e a mentalidade de que cabe às mulheres a prevenção de assédios, abusos e estupros"7.

Em contrapartida, na escola privada, o uso do uniforme no ensino médio é facultativo. Portanto, os alunos vestiam o que desejavam, alguns usavam o uniforme, outros não, sem julgamentos entre eles e sempre com muito respeito (independentemente, por exemplo, de as alunas virem ou não com shorts curto - o que era proibido na escola pública). Pudemos observar que o uso facultativo do uniforme permitia uma valorização das identidades e diversidades, proporcionando sentimento de pertencimento por parte dos alunos. A indumentária é um símbolo de comunicação que facilita na constituição dos grupos no estabelecimento de relações sociais e na busca do pertencimento (Costa \& Pires, 2007).

Sem o uso obrigatório do uniforme, os estudantes podem se vestir da maneira que querem e têm a oportunidade de mostrar suas identidades, com mais liberdade de expressão (Costa \& Pires, 2007). Nesse sentido, ao longo do trabalho de campo observamos nas salas e nos corredores uma grande diversidade de alunos, com perfis diferentes, que se vestiam e se expressavam de formas diferentes. Nesse universo, fica muito claro que todos buscam se respeitar e coexistem com as diferenças; e isso é a diversidade, como observa Sodré (2006). Não ficou claro em nenhum momento discriminação ou exclusão de forma evidente. Os estudantes se agrupam de acordo com suas afinidades, mas mesmo nos grupos, os alunos são heterogêneos, não se percebe uma constante no perfil e, quando necessário, interagem com os demais sem problemas e com respeito. O professor de sociologia Leonel (9/07/2018) comenta:

Eu acho muito legal essa abertura que a escola dá para a pluralidade assim. Eu já ouvi de muitos alunos que se sentem mais à vontade aqui do que em outras escolas. [...] Sobre a sexualidade eu acho muito legal o jeito que a [escola] aborda, principalmente o jeito que os colegas lidam entre si assim. Claro que rolam coisas tristes, tipo comentários que rolam em qualquer lugar, mas ao mesmo tempo eu vejo que eles têm liberdade. Eu vejo os alunos muito à vontade e a gente têm alunos trans, alunos

\footnotetext{
${ }^{6}$ Fala de Marina Stein, estudante entrevistada pela reportagem.

7 Texto elaborado pelas meninas na petição online "Vai ter shortinho, sim".
} 
gays e tudo mais, eu vejo na [escola] isso um ponto muito alto. Parece que aqui se concentra essa galera que não se adaptou nessas escolas e eu acho isso fantástico.

Essa fala do professor diz respeito a uma realidade muito interessante que acontece nessa escola: o entendimento do cotidiano dos jovens como forma de desenvolver a cidadania, que auxilia na intervenção, atuação e interação com os alunos, "a partir de suas realidades, de seus momentos de convívio no ambiente escolar, de suas falas, de seus grupos e de suas diferentes formas de interação", compreendendo um pouco mais sobre a vida destes alunos, para além da sala de aula (Costa \& Pires, 2007, p. 52). Uma vez que os alunos "convertem o espaço escolar em um lugar para encontrar os amigos, sair de casa, construir suas identidades" (Stecanela, 2016, p. 354), sendo um momento de constituição "das relações sociais com múltiplas mediações e interesses, voltados para as necessidades pessoais e os vínculos sociais e afetivos" (Costa \& Pires, 2007, p. 63). Nesse sentido, interpretamos que na escola privada

[...] a intervenção educativa que tenha a aprendizagem da cidadania como objetivo é, ela própria, um projeto politicamente comprometido: porque cria condições para a expressão e escuta da voz dos participantes, capacitando-os enquanto atores ativos e valorizando a diversidade de formas em que essa voz se pode expressar, porque encoraja a expressão de dissensões e pluralismo, e porque afirma o direito dos alunos e dos professores a tomarem decisões e exercerem poder sobre a suas próprias vidas na escola, reconhecendo que, para além das oscilações das políticas educativas, a vivência e o aprofundamento da democracia são tarefas inevitáveis no cotidiano escolar. (Menezes \& Ferreira, 2014, p. 144).

Portanto, o cotidiano do aluno, seu convívio no espaço escolar e suas construções de vínculos sociais e afetivos também são elementos que devem ser levados em conta na construção da cidadania, e não ignorados como foram historicamente.

Através do que acompanhamos ao longo do trabalho de campo, fica evidente a forte presença de regras e normas da escola pública. A supervisora comentou que a implementação de regras por vezes ainda é difícil, que hoje elas são aceitas, mas se demorou uns três anos para firmá-las (Julia, 12/07/2018). Nesse sentido, Boto (2018, p. 157-158) contribui que a escola "cumpre missão civilizadora", por isso tem a necessidade de "formar hábitos que tornem bem comportada a meninice", ensinando "padrões de pudor, de vergonha e de autocontrole; os quais, por suposto, deveriam regular 
o comportamento adulto". A supervisora afirma que isso também é uma questão de cidadania, bem como a professora de sociologia entrevistada, que acrescenta:

É uma instituição e vai ter regras e eles têm que trabalhar com isso, com essas questões também porque na sociedade em que a gente vive tem regras, tem leis a serem cumpridas, podem ser questionadas, mas tem que ser cumpridas, podem ser mudadas. (Eliza, 10/07/2018).

A professora diz na entrevista o que até então não havia sido dito: que as regras na escola "são colocadas em reunião com os pais, com a comunidade escolar e alunos todo início de ano; então é de conhecimento, é de participação, a comunidade escolar participa, concorda ou não concorda e é de conhecimento de todos" (Eliza, 10/07/2018). Entretanto, nas observações isso não foi constatado, visto que não estivemos na escola em período integral e a inserção nela ocorreu após o início do ano letivo. Apesar disso, pensamos que o diálogo, a problematização e o questionamento sobre as regras são importantes para que os alunos compreendam, se conscientizem e tenham a liberdade de se expressar e ter voz dentro da escola, para além de uma reunião, construindo, assim, sua cidadania. Corroborando com isso, Leão e Santos (2018, p. 792) apontam que, para os alunos, os espaços de participação representativa em órgãos colegiados "assumiam um papel meramente formal para referendar decisões já encaminhadas", sendo que os estudantes "chamavam atenção para o fato de que a participação e tudo que a envolvia (interação, negociação, respeito às regras) deveriam ser vistos como um aspecto central do processo educativo escolar", ou seja, de formação e desenvolvimento da cidadania.

A docente contribui dizendo que a escola apresenta "uma certa rigidez, uma certa disciplina, no entanto é uma escola que é bastante elogiada na sua forma organizada, a impressão que dá é que ela traz uma organização maior" (Eliza, 10/07/2018), e isso, de fato, pode ser facilmente observado ao entrar e frequentar a escola. A professora acrescenta que "por incrivel que pareça, os nossos adolescentes eles querem alguns limites [...] é necessário que haja esse direcionador" (Eliza, 10/07/2018). Aponta que é importante até mesmo quando uma regra é questionada, pois

[...] isso é cidadania também, é tu saber que grande parte da maioria da comunidade escolar optou pelo uniforme, por exemplo, pelo rigor do horário, por sentido de segurança, é mais seguro para o aluno estar de 
uniforme na rua hoje, é mais seguro para o aluno esta questão da rigidez de horário, é mais produtivo para as aulas, os alunos entram naquele horário e não tem interrupção nem nada. (Eliza, 10/07/2018).

De acordo com Boto (2018, p. 157), a escola tem um rito, a partir de sua cultura escolar, e tem também sua transgressão, pois "onde há norma, há resistência. Há conflito. Há sempre os que buscarão burlar a regra. E há, ainda, os que desconhecem a regra", devendo a escola como rito "ensinar e recordar as normas e as regras de vida coletiva, até para ensaiar com as gerações novas o rito da vida em coletividades". Para além disso, debater, discutir e construir cotidianamente e coletivamente essas normas e regras. Conforme a fala da professora Eliza, a rigidez com o uso do uniforme e horário de entrada e saída foi votada e escolhida por todos (direção, professores, pais e alunos - de acordo com o papel formal), por questões que extrapolam o estar na escola, mas também pela segurança. Ponderando sobre a questão do uniforme, Beck (2014, p. 143) afirma que ao longo da história o fator segurança retomava a obrigatoriedade do uso do mesmo, pois, assim, "logo se promoveria a identificação dentro e fora das escolas com os/as estudantes devidamente uniformizados".

A docente afirma: "Então é uma instituição com suas regras, bem como todas as instituições que têm, bem como a nossa própria sociedade que tem leis [...] tanto no sistema privado, como público, [...] isso também faz parte da construção da cidadania" (Eliza, 10/07/2018). Além disso, a professora reitera que quando o aluno é confrontado com a regra, com o limite, percebe "que na verdade é um ensaio também dentro da construção desse cidadão, que vai ter que seguir regras nessa sociedade e ao mesmo tempo é um espaço democrático, ele pode questionar e ele pode entender ou não entender" (Eliza, 10/07/2018). Durante as observações interpretamos que essa docente era uma das poucas que abria espaços de discussões e questionamentos, o que nos leva a pensar que essa deveria ser uma atitude adotada por todos os docentes.

A construção de "normas de disciplinas e de organização da escola, com a participação direta dos/as estudantes" é defendida pelas diretrizes nacionais para educação em Direitos Humanos (Brasil, 2013, p. 48). Portanto, por um lado, temos uma escola pública que tem como característica marcante as regras, assim como propõe essas diretrizes, com a participação dos alunos e comunidade escolar (pelo relatado nas entrevistas e encontrado no PPP). Por outro, temos uma escola privada com maior flexibilização quanto às 
normas, diálogo e construção diária das mesmas. Ambas funcionam dentro de suas organizações escolares e, pelo que parece, suprem as necessidades de seus alunos e da comunidade escolar que integram. Acreditamos que os extremismos não são saudáveis para a construção da cidadania, por isso defendemos que na escola pública merecia haver um diálogo mais aberto, provocando questionamento nos alunos, até mesmo na instituição das regras, uma vez que é:

\begin{abstract}
Preciso acreditar que cada sujeito pode contribuir para construção das regras de convívio coletivo e não simplesmente cumpri-las. [...] Deve ser um espaço de encontro, de estímulo à sociabilidade, que permita vivenciar a construção coletiva das normas, criando estratégias de acesso, pertencimento, permanência e qualidade, pautadas no respeito ao outro e na inclusão de todos. (Costa \& Pires, 2007, p. 64).
\end{abstract}

Portanto, os alunos também têm a capacidade e a vontade de contribuir nesses processos decisórios, não apenas através da participação - formal representativa em órgãos colegiados, mas sendo reconhecidos como atores legítimos nas discussões sobre os rumos da escola (Leão \& Santos, 2018). Dentre as dificuldades para se desenvolver a cidadania no âmbito escolar, Stecanela (2016, p. 353) aponta para a "força das culturas que adentram a escola e desestabilizam práticas distanciadas de diálogo", como observado na escola pública. Além disso, os alunos reivindicam que o ambiente escolar seja "um tempo e um espaço de exercício de cidadania, através do qual acreditam ter o que dizer e com o que contribuir para a escola se aproximar de suas expectativas" (Stecanela, 2016, p. 353). Ainda que a formação cidadã e o fomento à autonomia dos alunos estejam presentes nos princípios e nas formulações das propostas pedagógicas, se verifica muitas resistências na efetivação de práticas pedagógicas e organizacionais que os concretizem (Leão \& Santos, 2018). Nesse sentido, vale lembrar que educar para cidadania compreende o "cultivo de valores socialmente acordados, não numa tentativa de homogeneizar os sujeitos aprendentes, mas de resgatar características que são genuinamente humanas" (Trevisan, 2009, p. 107).

\title{
4. Conclusão
}

Buscando analisar os desdobramentos da cidadania na dimensão do cotidiano escolar compreendemos a forte influência da cultura escolar, seja no sentido da instituição escola em si, seja nos recintos analisados em específico. Em 
vista disso, fica evidente que a escola pública partilha de uma cultura já instituída na sociedade que caracteriza a escola, por meio da sua organização e do método tradicional de ensino, como também possui certa cultura na cidade em que se localiza, por meio de sua história e tradição na região. Em contrapartida, a escola privada com a mudança para as metodologias ativas e colaborativas e reorganização do seu espaço e funcionamento escolar, acabou por reconstruir essa cultura, iniciando a formulação de outros arranjos, combinações e decisões. Dessa forma, alunos, professores e comunidade estão aprendendo nesse processo.

O fator que mais chamou atenção foram as regras de convívio social presentes no cotidiano escolar, que são muito discrepantes entre os contextos estudados, já que na escola pública apresentam-se bem definidas e rígidas e na escola privada apresentam-se flexíveis. Na escola pública, pudemos acompanhar que a visão predominante é de que as regras são necessárias porque no trabalho e na sociedade os alunos terão que seguir regras, enquanto que na escola privada a lógica também segue essa perspectiva, mas de uma maneira distinta, já que os alunos deverão ter conhecimento e consciência das normas da sociedade e trabalho, sem ninguém vir cobrálas, projetando esse aluno mais autônomo e responsável por seus atos.

Na escola pública, a existência dessas regras parece ocorrer muito mais no sentido de dever do que de convívio, de obrigação de determinada conduta de comportamento de acordo com as normativas e de enquadramento do comportamento social nesse modelo estipulado, o que acaba limitando a cidadania plena. Na escola privada há muito diálogo, construção, questionamentos e autonomia dos alunos para se expressarem dentro da instituição, desenvolvendo o protagonismo do aluno, da construção da escola, fomentando a possibilidade de se desenvolver socialmente e de ter voz e vez na construção diária da escola e da sua formação.

Fica evidente que ambas as formas de lidar com o cotidiano escolar, a partir de normas, funcionam nos respectivos lugares, tornando-os organizados dentro de suas estruturas. Entretanto, frisamos que ainda assim o diálogo com o aluno na escola pública poderia ser mais estimulado e aberto para uma construção de cidadania que encare os sujeitos com sua voz, alteridade e identidade. Na escola privada, o novo modelo que flexibiliza normas e 
perspectiva o aluno como autônomo, precisa ser melhor delineado para que todos os envolvidos (alunos, professores, equipe diretiva e pais) possam compreender e contribuir, tomando como ponto de partida a elaboração do PPP.

\section{Referências}

Beck, D.Q. (2014). Uniformes escolares: delineando identidades de gênero. Revista HISTEDBR On-line, 58, 136-150. Recuperado de http://bit.ly/3ukeq1v

Bonilla, M.H.S. \& Pretto, N.L. (2015). Política educativa e cultura digital: entre práticas escolares e práticas sociais. Perspectiva, 33(2), 499-521. Recuperado de http://bit.ly/3kfVOuJ

Boto, C. (2018). A civilização escolar pelos compêndios didáticos de formação de professores. Educar em Revista, 34(70), 155-178. Recuperado de http://bit.ly/2ZGDstr

Brasil (2013). Secretaria de Direitos Humanos da Presidência da República. Educação em Direitos Humanos: Diretrizes Nacionais. Brasília: Coordenação Geral de Educação em SDH/PR, Direitos Humanos, Secretaria Nacional de Promoção e Defesa dos Direitos Humanos. Recuperado de https://bit.ly/2NWeTWY

Candau, V.M.F. (2002). Sociedade, cotidiano escolar e cultura(s): uma aproximação. Educação \& Sociedade, XXIII(79), 125-161. Recuperado de https://bit.Iy/3soneSb

Cauduro, M.T. (Org.). (2004). Investigação em Educação Física e Esportes: um olhar pela pesquisa qualitativa. Novo Hamburgo: Feevale.

Costa,A.G. \& Pires, G.L. (2007). Moda/indumentária em culturas juvenis: símbolos de comunicação e formação de identidades corporais provisórias em jovens do ensino médio. Revista Conexões, 5(1). Recuperado de http://bit.ly/3dF4hGr

Ferreira, F.C. \& Castellani Filho, L. (2012). Escola e Formação para a cidadania: qual o papel da Educação Física? Movimento, 18(4), 135-154. Recuperado de http://bit.ly/2ZNthmJ

Giassi, M.G., Dajori, J.F., Machado, A.C., \& Martins, M.C. (2016). Ambiente e cidadania: educação ambiental nas escolas. Revista de Extensão, 1(1). Recuperado de hhttp://bit.ly/3uolSsm

Leão, D.M.M. (1999). Paradigmas contemporâneos de educação: escola tradicional e escola construtivista. Cadernos de Pesquisa, 107, 187-206. Recuperado de https://bit. ly/3aloWaY

Leão, G. \& Santos, T.N.A. (2018). A participação juvenil no Ensino Médio brasileiro: um campo de estudos em construção. Práxis Educativa, 13(3), 787-804. Recuperado de https:// bit.ly/3uqzqug

Maia, A.A.M. \& Pereira, M.Z.C. (2014). Cidadania, Educação e Cotidiano. Educação \& Realidade, 39(2), 617-631. Recuperado de http://bit.ly/3qKyRCk

Malikoski, A. \& Kreutz, L. (2014). A Cultura Escolar como categoria de análise na produção de narrativas históricas sobre a Educação. Textura, 32, 245-260. Recuperado de http:// bit.ly/3up8Meo 
Martins, M.J.D. \& Mogarro, M.J. (2010). A educação para a cidadania no século XXI. Revista Iberoamericana de Educación, 53, 185-202. Recuperado de https://doi.org/10.35362/ rie530566

Mattos, R.S. (2016). Pesquisa Qualitativa em educação física: da graduação ao doutorado. Curitiba: CRV.

Menezes, I. \& Ferreira, P. (2014). Cidadania participatória no cotidiano escolar: a vez e a voz das crianças e dos jovens. Educar em Revista, 53, 131-147. Recuperado de http:// bit.ly/3kden2N

Pinto, N.B. (2014). História das disciplinas escolares: reflexão sobre aspectos teórico-metodológicos de uma prática historiográfica. Rev. Diálogo Educ., 14(41), 125-142. Recuperado de http://bit.ly/3aPpHzb

Projeto Político-Pedagógico (2017). Escola Pública pesquisada.

Projeto Político-Pedagógico (2007). Escola Privada pesquisada.

Rifiotis, T. (2007). Sujeito de direitos e direitos do sujeito. In Silveira, R.M.G., Dias, A.A., Ferreira, L.F.G., Feitosa, M.L.P.A.M., \& Zenaide, M.N.T. (Orgs). (2007). Educação em Direitos Humanos: fundamentos teórico-metodológicos (231-244). João Pessoa: Editora Universitária. Recuperado de https://bit.ly/3dDiuDX

Silva, M.R. (1995). Educação e a formação do cidadão. Educar, 11, 129-134. Recuperado de http://bit.ly/2OVrppW

Silverman, D. (2009). Interpretação de dados qualitativos: métodos para análise de entrevistas, textos e interações. Porto Alegre: Artmed.

Sodré, M. (2006). Diversidade e diferença. Revista Cientifica de Información y Comunicación, 3. Recuperado de http://bit.ly/2ZKojak

Stecanela, N. (2016). O direito à educação e o cotidiano escolar: dimensões do concebido, do vivido e do percebido. Educação (Porto Alegre), 39(3), 344-356. 2016. Recuperado de http://bit.ly/3dHhONQ

Trevisan, I. (2009). Práticas de cidadania em narrativas de professores de ciências: trabalho coletivo de ensino e de aprendizagem. Dissertação de mestrado apresentada ao Programa de Pós-Graduação em Educação em Ciências e Matemática da Universidade Federal do Pará, Belém. Recuperado de http://bit.ly/2NxM82H

Vinuto, J. (2014). A amostragem em bola de neve na pesquisa qualitativa: um debate em aberto. Temáticas, 22(44), 203-220. Recuperado de http://bit.ly/2ZInEq0 